\title{
DECONTAMINATION OF HYDROCHLORIC AND NITRIC ACIDS
}

\author{
Nikolay Iliyanov PADAREV*, Danut-Eugeniu MOSTEANU** \\ *"Vasil Lewski” National Military University- Veliko Tarnovo, Bulgaria \\ **"Nicolae Bălcescu" Land Forces Academy, Sibiu, Romania \\ nikolai_padarev@abv.bg, dmosteanu@gmail.com
}

\begin{abstract}
One of the missions of the Bulgarian Army is the formation of maintenance modules that can take part in a series of military activities, including the eradication of the consequences of natural disasters, chemical and radiological accidents and ecological catastrophes. One task of the module formations in chemical and radioactive incidents is decontamination of equipment, materials and people. Pollution with toxic substances can occur in the area of military operations, tank spills, and terrorist attacks in peacetime. The Hazard Index ranks TIMs according to the chemical's production, transport, storage, toxicity, and vapor pressure. Mineral acids considered ", high hazards" are also having a high level of toxicity and vaporize easily. This paper provides some chemical tasks about acids decontamination on non-porous materials. We have investigated the decontamination of hydrochloric and nitric acid in the non-porous surfaces through calculations and their decontamination on wood and concrete surfaces.
\end{abstract}

Keywords: decontamination, hydrochloric acid, nitric acid.

\section{Introduction}

In everyday life a lot of toxic substances can be found in the environment affecting all life forms (plants [1-6], animals, and humans) by polluting different environmental areas: air, soil, water [7-16]. Many of these substances come from excessive industrialization, fertilizer-based farming and intensive chemicals, and a poor industrial and household waste management [7-21].

As a result, many companies and factories (production units) carefully follow the production process from the design or the idea of a product to the final stage of its life (the waste) [10, 22-27], in addition to an intense concern for the development and production growth [22-29]. As a beneficial consequence, the existence of these control activities regarding the wastes in the field of industrial production allows a permanent qualitative improvement of the environment conditions. An important positive factor that can be also reminded here is the education of the people in the field of waste management and environmental protection [29-31].

One of the missions of the Bulgarian Army is the formation of maintenance modules that can take part in a series of military activities, including the eradication of the consequences of natural disasters, chemical and radiological accidents and ecological catastrophes [31, 32].

Determination of the industrial toxic substances and their concentration in chemical accidents is the first stage in the activity related to assessing the impact of chemicals on the environment [31,32]. For effective decontamination of the chemical accidents it is important to use fast and accurate methods. It is essential that the 
type and characteristics of decontamination solution and its amount to be proper for decontamination. Mineral acids considered "high hazards" also have a high level of toxicity and vaporize easily.

Muriatic acid is a highly reactive liquid acid, and one of the most dangerous chemicals. With the exception of some plastics, muriatic acid can damage almost anything it touches, including clothing, metal, and skin. It emits a suffocating odor that can quickly burn the nasal mucosa, throat and even the lungs [33]. Chemical accidents with nitric acid are very dangerous and many cases have been recorded [34,35]. Study on the decontamination of acids or other harmful substances on different surfaces or in the environment is relevant as they influence the risk assessment for industrial accidents, also being relevant the method used for their determination [1,2,36-39].

Several studies have been carried out in the attempt to explore adsorbtion of hydrochloric and nitric acids in concrete and pine wood. The scientific reports have not found exposure of pinewood to mineral acids, but we found the effect of acid rain on the pinewood. The literature contains tabulations on the exposure of concrete to various acids [40,41], but their decontamination was not found.

The purpose of this paper is to develop a methodology and analyze for qualitative and quantitative assessment of the wetting of inorganic acids on porous surfaces and to compare it to non-porous materials and their decontamination.

\section{Material and methods}

Hydrochloric and nitric acids solutions (as many other chemical substances) are characterized by different adsorption in materials.
We prepared $\mathrm{HNO}_{3} 58 \%$ and $\mathrm{HCl} 35 \%$. Based on calculations, we have found the values of concentrations of bases that neutralize the solutions used in this study, in non-porous materials. The values are refer at a temperature of $293.15 \mathrm{~K}\left(20{ }^{\circ} \mathrm{C}\right)$ and a pressure of $100 \mathrm{kPa}(1 \mathrm{~atm})$.

Another potential challenges ware to determine the type and size of the surface on which to spill the acid. When the matrix is a potentially contaminated surface, the spiking chemicals are absorbed in the wood or concrete and acids need to be neutralized.

Wooden and concrete surfaces are $20 \times 20 \times 20 \mathrm{~mm}$ size were arranged in a glass box. The boundary between the test surfaces and the glass was sealed with silicone.

The acid was conducted under $90^{\circ}$ angle from the surface by pulling off the pipette. The surface area was $4 \mathrm{~cm}^{2}$. The drop weight varied, the experiment temperature was $26{ }^{\circ} \mathrm{C}(299 \mathrm{~K})$, humidity $34 \%$ and atmospheric pressure $1027 \mathrm{hPa}$.

$\mathrm{pH}$ measurements are commonly used as methods of measuring acidity or basicity aggressiveness, but in this case they are not suitable, so we used a $\mathrm{pH}$ indicator paper.

\section{Results and discussions}

The attribute "decontaminating power" is the amount of TIM degraded by $1 \mathrm{~cm}^{3}$ decontaminant at a specified temperature for a certain time interval. Decontamination of hydrochloric and nitric acid was determined by using a mathematical model, based on the concentration of involved alkaline substances which are indicators of decontamination ability. The alkali substances are used in concentrations of $0.5 \%, 1 \%, 1.5 \%, 2 \%, 2.5 \%, 3 \%$. The results are shown in Figure 1 and Figure 2. 


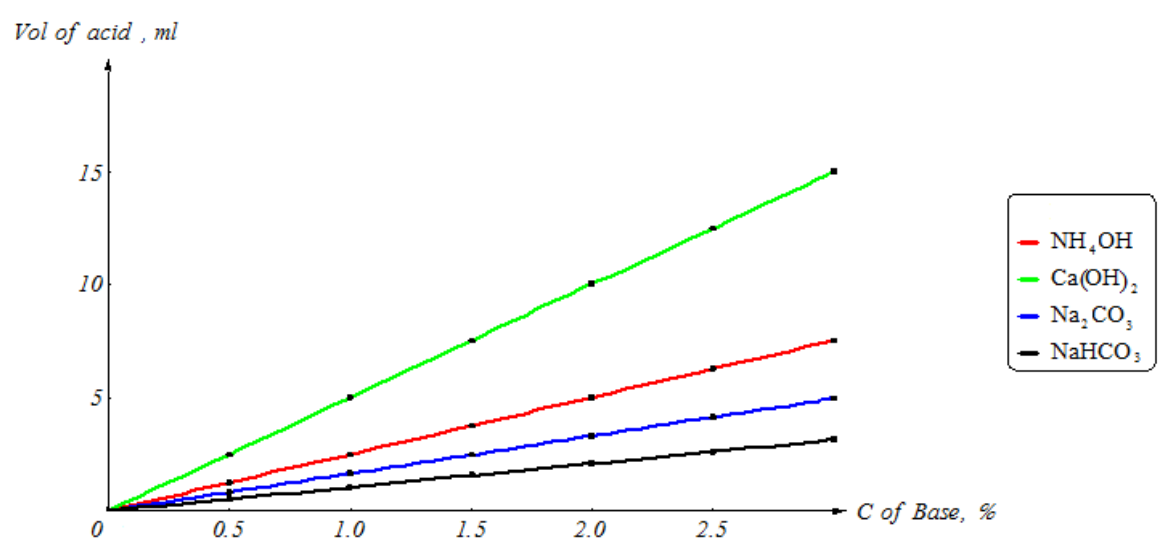

Figure 2: Hydrochloric acid decontamination with bases

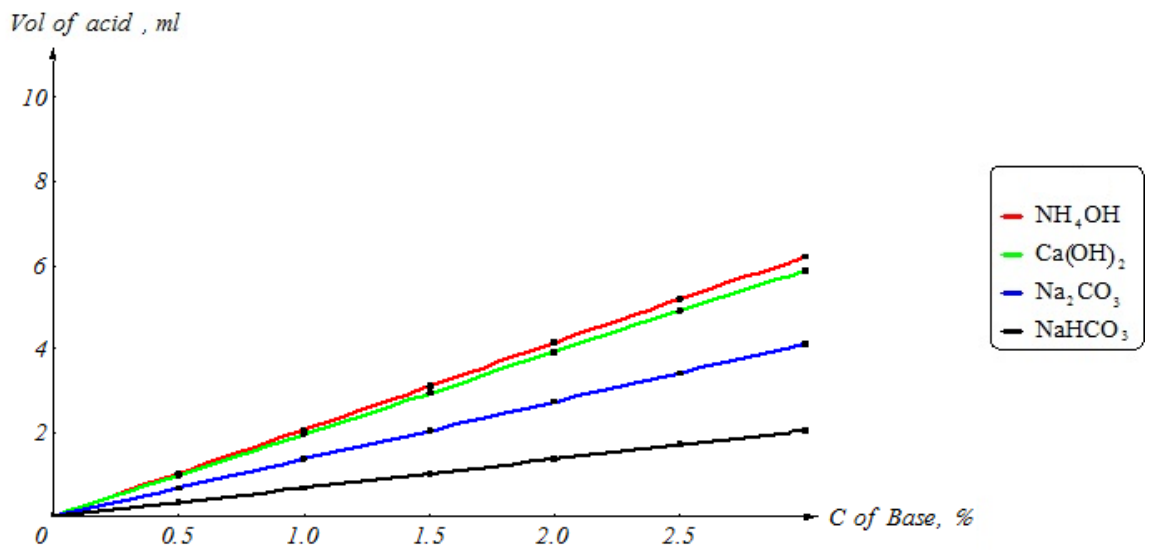

Figure 2: Nitric acid decontamination with bases

In the laboratory conditions, we have examined wooden and concrete surfaces that were placed on the glass box. The idea was to contaminate different surfaces of the same size with the same amount of acid and base, and then to examine the decontamination efficiency. When the drop of liquid falls on a solid surface there is a flow, which is associated with a change in the area between the phases of the equilibrium state (Figure 3).

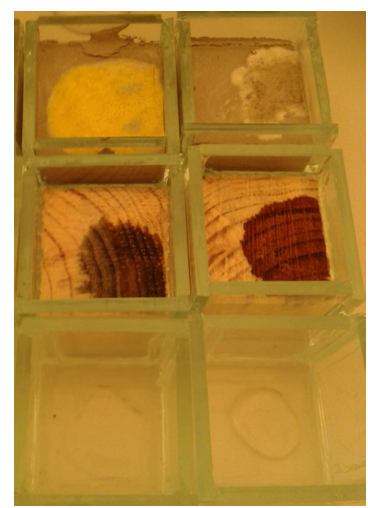

Figure 3: Acid spills on concrete, wood and glass

We have found that the diameter of the stain Figure 3 increases in contrast to the glass on contact with acid and wood acid droplets. At the end of the liquid phase, the 
process speed is reduced. Wetting can be seen because of the action of surface tension forces. The equilibrium value of the wetting angle is determine by the Yung equation [42].

Both acids may initially attack concrete at about the same rate, but on an equal volume basis, a given volume of the weak acid ultimately will be more destructive. Acid solutions attack concrete through dissolution and acid base chemical reactions. The reaction attacks concrete on the exposed surface and works inward. Hydrochloric acid stains the concrete in yellow and the nitrogen in white, so in an accident where the acid is unknown, coloring is also a sign of the species.

For the decontamination of acids with bases in wood and concrete $\mathrm{NH}_{4} \mathrm{OH}$ is the best base, but $\mathrm{Ca}(\mathrm{OH})_{2}$ is cheaper then
$\mathrm{NH}_{4} \mathrm{OH}$ [43]. Therefore $\mathrm{Ca}(\mathrm{OH})_{2}$ is the optimal economic decontamination substance for this experiment.

\section{Conclusions}

Analytical methods are known to detect the type of acid, but in case of breakdown, there is a time limit. Investigation of acid spills on hard surfaces is a complicated process because of the different adsorption surfaces. Besides "decontaminating power" we must know the following parameters: the distribution area of TIM at the time of disposal, the density of the substance in the stain, and the presence of liquid phase.

New matrices, such as concrete and pinewood, were selected to provide matrix challenge for how some alkali substances work up.

\section{References}

[1] Bungau S., Baldea I., Copolovici L., Revista de Chimie-Bucharest, Vol. 54, No. 3, pp. 213-216, 2003.

[2] Copolovici D., Bungau S., Boscencu R., Tit D. M., Copolovici L., Revista de Chimie-Bucharest, Vol. 68, No. 3, pp. 507-509, 2017.

[3] Gitea D., Vicas S., Gitea M. A., Nemeth S., Tit D. M., Pasca B., Purza L., Iovan C., Revista de Chimie-Bucharest, Vol. 69, No. 2, pp. 305-309, 2017.

[4] Mot C. A., Lupitu A. I., Bungau S., Copolovici D. M., Purza L., Melinte (Frunzulica) C. E., Copolovici L., Revista de Chimie-Bucharest, Vol. 69, No. 5, in press, 2018.

[5] Oprea O. B., Apostol L., Bungau S., Cioca G., Samuel A. D., Badea M., Gaceu L., Revista de Chimie-Bucharest, Vol. 69, No. 1, pp. 70-75, 2018.

[6] Pallag A., Bungau S. G., Tit D.M., Jurca T., Sirbu V., Honiges A., Horhogea C., Revista de Chimie-Bucharest, Vol. 67, No. 3, pp. 530-533, 2016.

[7] Rada E.C., Cioca L.I., Energy Procedia, Vol. 119C, pp. 72-85, 2017.

[8] Rada E.C., Cioca L.I., Ionescu G. Energy recovery from Municipal Solid Waste in EU: proposals to assess the management performance under a circular economy perspective. In MATEC Web of Conferences, Vol. 121, pp. 05006, 2017

[9] Ragazzi M., Maniscalco M., Torretta V., Ferronato N., Rada E.C., Energy Procedia, Vol. 119, pp. 602-614, 2017.

[10] Bungau S., Bungau C., Tit D. M., Journal of Environmental Protection and Ecology, Vol. 16, No. 1, pp. 56-62, 2015.

[11] Bungau S., Suciu R., Bumbu A., Cioca G., Tit D. M., Journal of Environmental Protection and Ecology, Vol. 16, No. 3, pp. 980-987, 2015.

[12] Nechifor G., Ajmone-Marsan F., Environmental Science. Processes \& Impacts, Vol. 16, No. 2, pp. 211-219, 2014. 
[13] Ionescu G., Rada E. C., Cioca L.I. Municipal solid waste sorting and treatment schemes for the maximization of material and energy recovery in a latest EU member, Proc. 10th International Conference on Environmental Legislation, Safety Engineering and Disaster Management, Cluj-Napoca, Romania, Vol. 14, No. 11, pp. 2537-2544, 2015.

[14] Tit D. M., Bungau S., Nistor Cseppento C., Copolovici D. M., Buhas C., Journal of Environmental Protection and Ecology, Vol. 17, No. 4, pp. 1425-1433, 2016.

[15] Popescu D. E., Bungau C., Prada M., Domuta C., Bungau S., Tit D. M., Journal of Environmental Protection and Ecology, Vol. 17, No. 3., pp. 1011-1020, 2016.

[16] Taschina M., Copolovici D. M., Bungau S., Lupitu A. I., Copolovici L., Iovan C., Farmacia, Vol. 65, No. 5, pp. 709-713, 2017.

[17] Ragazzi, M., Maniscalco, M., Torretta, V., Ferronato, N., Rada, E.C. (2017). Anaerobic digestion as sustainable source of energy: A dynamic approach for improving the recovery of organic waste. Energy Procedia, 119, 602-614.

[18] Samuel A. D., Brejea R, Domuta C., Bungau S., Cenusa N., Tit D. M., Journal of Environmental Protection and Ecology, Vol. 18, No. 3, pp. 871-878, 2017.

[19] Samuel A. D., Tit D. M., Melinte Frunzulica C. E., Iovan C., Purza L., Gitea M., Bungau S., Revista de Chimie-Bucharest, Vol. 68, No. 10, pp. 2243-2247, 2017.

[20] Copolovici L., Timis D., Taschina M., Copolovici D, Cioca G., Bungau S., Revista de Chimie-Bucharest, Vol. 68, No. 9, pp. 2076-2078, 2017.

[21] Gitea M. A., Bungau S., Gitea D., Purza L., Nemeth S., Samuel A. D., Badea G., Tit D. M., Revista de Chimie-Bucharest, Vol. 69, No. 6, in press, 2018.

[22] Bungau C., Blaga F., Gherghea C., Method of Analysis and Audit Used to Implement 5s in Operational Management, Proceedings of the 2nd Review of Management and Economic Engineering Management Conference: Management of Crisis or Crisis of Management?, pp. 36-47, Cluj Napoca, Romania, 2011.

[23] Cuc S., Bungau C., Creating competitive advantage through sustainable value chain: insights on automotive and textile industry, Management between profit and social responsibility, Review of Management and Economic Engineering International Management Conference, pp. 186-196, Cluj Napoca, Romania, 2014.

[24] Cuc S., Tripa S., Bungau C., Strategies for Increasing Competitiveness of the Romanian Textile and Clothing Industry, 5th Review of Management and Economic Engineering International Management Conference, p. 100-+, Cluj Napoca, Romania, 2016.

[25] Bungau, C., Gherghea, I.C., Prichici, M., Value Stream Mapping Analysis, Efficiency Methods of Operational Management, Twenty Years after: How Management Theory Works, Proceedings, Review of Management and Economic Engineering International Management Conference, pp. 188-198, Cluj-Napoca, Romania, 2010.

[26] Bungau, C., Blaga, F., Gherghea, C., Kaizen Implementation for Cost Reduction in Manufacturing Process Product "Driver Control Board", 2014 International Conference on Production Research - Regional Conference Africa, Europe and the Middle East and 3rd International Conference on Quality and Innovation in Engineering and Management, pp. 55-58, Cluj-Napoca, Romania, 2014.

[27] Csokmai, L.S.,Tarca, R.C., Bungau, C., Husi, G., International Journal of Computers Communications \& Control, Vol. 10, No. 1, pp. 30-37, 2015.

[28] Giurgiu, L., Barsan, G., Mosteanu, D., The technical dimension of knowledge management in the context of learning and training, The 9th International Management Conference: Management and Innovation For Competitive Advantage, pp. 506-512, Bucharest, Romania, 2015. 
[29] Mosteanu D., Halmaghi, E.E., The challenges of sustainable development, 18th International Conference - The Knowledge-Based Organization: Management and Military Sciences, Conference Proceedings 1, pp. 548-552, Sibiu, Romania, 2012.

[30] Badulescu, D, Bungau, C., Badulescu, A., J. Journal of Environmental Protection and Ecology, Vol. 16, No. 3, pp. 1101-1108, 2015.

[31] Mosteanu, D., Trefas, L., Trefas, A.-S., Mosteanu, R., Risk other than attack substances transportation, The 21st International Conference Knowledge Based Organization, Nicolae Balcescu Land Forces Academy, pp. 857-860, Sibiu, Romania, 2015.

[32] ***, White Book on the Defense and Armed Forces of the Republic of Bulgaria, Sofia, pp. 15-25, 2010.

[33] Ebbing D.D., Gammon S.D., General Chemistry, 11 Ed., USA, pp. 82-121, 2017.

[34] ***, Safety Data Sheet, Regulation (EC) No. 1272/2008, Valeros, 2012.

[35] http://www.factsonline.nl/accidents/\%205405/92031_NITRIC\%20ACID/chemicalaccidents-with-nitric-acid

[36] Mosteanu, D., Bârsan, G., Giurgiu, L., Epure G., Revista de Chimie-Bucharest, Vol. 60, No. 3, pp. 290-293, 2009.

[37] Mosteanu D., Barsan G., Otrisal P., Giurgiu L., Oancea R., Revista de Chimie-Bucharest, Vol. 68, No. 11, pp. 2499-2502, 2017.

[38] Badea M., Chiperea C., Balan M., Floroian L., Restani P., Marty J.-L., Iovan C., Ţiţ D. M., Bungău S., Taus N., Farmacia, Vol. 66, No. 1, pp. 83-7, 2018.

[39] Otrisal P., Florus S., Barsan G., Mosteanu D., Revista de Chimie-Bucharest, Vol. 69, No. 2, pp. 300-304, 2017.

[40] ***, A guide to the Use of Waterproofing, Damp proofing, Protective and De Decorative Barrier Systems for Concrete, ACI Manual of Concrete Practice, Part 5, American Concrete Institute, Detroit, 1990.

[41] ***, Effect of Various Substances on Concrete and Guide to Protective Treatments, PCA Concrete Informatoon Sheet Portland Cement Association, 1989.

[42] Padarev B., Surface Activity of Solutions for Decontamination, Dissertation, Sofia, pp. 25-28, 2015.

[43] https://www.lime.org/documents/publications/free_downloads/acid-neut-final-2000.pdf 